\title{
THE ESTIMATION OF FREB ALUMINIUM AND THE COMPETITION BETWEEN FLUORIDE AND HUMATE ANIONS FOR ALUMINIUM
}

G.S.P. Ritchie, M.P. Nelson and M.G. Whitten

\section{ABSTRACT}

Three equations for estimating the concentration of free aluminium, $\left[\mathrm{Al}^{3+}\right]$, from the activity of free fluoride, $\left(\mathrm{F}^{-}\right)$, were compared to assess their suitability for estimating [A ${ }^{3+}$ ] in acid soil solutions and in competition studies. We then studied the ability of humic acids to compete with F for Al by comparing the behaviour of the humic acids in the presence of $F$ and $A l$ with that of several carboxylic acids under the same conditions.

All three methods of estimating $\left[\mathrm{Al}^{3+}\right]$ were 1 imited in their applicability to acid soil solutions but were suitable for estimating $\left[\mathrm{Al}^{3+}\right.$ ] in competition studies when equimolar quantities of $A I_{T}$ and $F_{T}$ were used. Humic acids extracted by $\mathrm{NaOH}$ and by $\mathrm{Na}_{2} \mathrm{H}_{2} \mathrm{P}_{2} \mathrm{O}_{7}$ 
decreased the amount of Al complexed with F by 21 $100 \%$ at $\mathrm{pH} 4$ and 6 and ratios of cmoles of humic

acid: $>>1$. The Al humate complex precipitated when the Al:humic acid ratio was >1. Both humic acids appeared to be more effective than simple carboxylic acids at competing with $F$ for Al.

\section{INTRODUCTION}

Both fluoride, $F$, and organic anions have been shown to decrease Al toxicity to plants by forming soluble complexes and thereby decreasing the amount of free aluminium, $A l^{3+2,6}$. ([] will be used to denote concentrations and () to denote activities throughout this report.) The anions have been identified in soil solutions as major complexing ligands of $\mathrm{Al}^{4,11}$ but the extent to which they compete for Al is not known. This is partly because it is difficult to estimate an equilibrium constant for the formation of Al-humate complexes and therefore thermodynamic equilibria principles cannot be used to predict the speciation of Al. The identification of $\mathrm{Al}^{3+}$ as the major toxic Al species has renewed interest in analytical methods for Al that measure $\mathrm{Al}^{3+}$ only, rather than total aluminium, $\mathrm{Al}_{\mathrm{T}}$. The reactions of $\mathrm{F}$ and organic 1 igands with $\mathrm{Al}^{3+}$ could be important in the selection of suitable methods of measuring $\mathrm{Al}^{3+}$ in soil solutions for two reasons. Firstly, it has been shown that some methods cannot distinguish between $\mathrm{Al}^{3+}$ and aluminium complexed with fluoride, $A_{F}$ (e.g. the hydroxyquinoline method ${ }^{7}$ and the resin method ${ }^{3}$ ). If $F$ can compete successfully with organic anions for $A 1, \mathrm{Al}^{3+}$ may be overestimated by such methods. Secondly, methods that could distinguish between $\mathrm{Al}^{3+}$ and $A l_{F}$ (by measuring the activity of free fluoride, $\left(\mathrm{F}^{-}\right)$, with an ion selective electrode) may 
underestimate $\left[\mathrm{Al}^{3+}\right]$ under certain conditions. Ion selective electrode (ISE) measurements of $\left[F_{T}\right]$ and ( ${ }^{-}$) have been used to estimate $\left[A 1^{3+}\right]$ and $A 1$ complexed with organic ligands 8 . In theory, this could be a very useful approach for studying the competition between humic acids and $F$ for $A l$ and for estimating $\left[A 1^{3+}\right]$ in acid soil solutions. In practice, however, the procedure is limited by the method of calculating $\left[A 1^{3+}\right.$ ] from $\left(F^{-}\right)$as well as the difficulties associated with $\left(F^{-}\right)$measurements at the low concentrations $\left(<10^{-6} \mathrm{M}\right)$ found in unpolluted soils.

The objectives of our research were to compare three equations for estimating $\left[\mathrm{Al}^{3+}\right]$ from $\left(\mathrm{F}^{-}\right)$and consider their suitability for estimating $\left[\mathrm{Al}^{3+}\right]$ in acid soil solutions and in competition studies. We then studied the ability of humic acids to compete with $F$ for Al to assess which anion would have the greater effect on soluble Al in acid soils.

\section{MATERIALS AND METHODS}

Estimation of $\left[A 1^{3+}\right]$ from the Activity of Free Fluoride, $\left(\mathrm{F}^{-}\right)$

A theoretical comparison was made between three equations for estimating $\left[\mathrm{Al}^{3+}\right.$ ] from the activity of free fluoride, $\left(\mathrm{F}^{-}\right)$, and $\left[\mathrm{Al}{ }^{3+}\right]$ estimated by a thermodynamic equilibrium program, QELIOS ${ }^{14}$, for a series of hypothetical solutions with varying $A_{T}: F_{T}$ ratios. The solutions had a $\mathrm{pH}$ of 4 , an ionic strength of $0.005 \mathrm{M}$ and contained $100 \mu \mathrm{M} \mathrm{AlCl}{ }_{3}$ and sufficient $K F$ to give $A I_{T}: F_{T}$ ratios of $\propto, 10,5,2.5,1.3,1.0$ and 0.5 . No experimental measurements were made because the purpose of the comparison was to assess the effect of the assumptions used to derive the equations on the estimate of $\left[\mathrm{Al}^{3+}\right]$. Experimental measurements of $\left(\mathrm{F}^{-}\right)$ 
would have introduced a confounding factor due to the difficulties of measuring $\left(\mathrm{F}^{-}\right)$at low concentrations ${ }^{5}$.

The comparison was carried out by calculating $\left(F^{-}\right)$ for each solution using QELIOS. The values of $\left(\mathrm{F}^{-}\right)$ were then used in equations (1) - (3) (described below) to estimate $\left[\mathrm{Al}^{3+}\right]$. The estimates of $\left[\mathrm{Al}^{3+}\right]$ from equations ( 1 ) $-(3)$ were then compared with $\left[\mathrm{Al}^{3+}\right]$ calculated by QELIOS. QELIOS is a computer program that estimates the concentration of free ions from a series of simultaneous equations derived from the conservation of mass of every element present. Each mass balance equation is written in terms of the total concentrations of the appropriate element and the thermodynamic equilibrium constants for the formation of complexes by that element. The method of calculation has been described in detail by sposito ${ }^{16}$. Aluminium was considered to form the hydroxy-complexes $\mathrm{AlOH}^{2+}$ and $\mathrm{Al}(\mathrm{OH})_{2}^{+}$whereas $\mathrm{AlF}^{2+}, \mathrm{AlF}_{2}^{+}$and $\mathrm{AlF}_{3}^{\circ}$ were the only $A 1-F$ complexes included in the calculations because preliminary calculations indicated that the sum of the concentrations of $\mathrm{AlF}_{4}^{-}, \mathrm{AlF}_{5}^{2-}$ and $\mathrm{AlF}_{6}^{3-}$ did not exceed $1.4 \times 10^{-8} \mathrm{M}$. The values of the equilibrium constants were taken from Lindsay 9 .

The first equation assumes that the equilibrium in solution can be described by the conservation of mass of fluoride alone. $\left[\mathrm{Al}^{3+}\right]$ is estimated from the mass balance equation by expressing the concentrations of Al-F complexes in terms of their equilibrium formation constants, $\mathrm{K}_{\mathrm{Fm}}^{\mathrm{O}}$ (m is the number of moles of $\mathrm{F}$ in each complex), $\left[\mathrm{Al}^{3+}\right] \gamma_{3}\left(\gamma_{\mathrm{n}}\right.$ is the activity coefficient for a species with a charge of $n$ ) and $\left(F^{-}\right)^{8,5}$ :

$$
\left[A I^{3+}\right]=\left\{\left[F_{T}\right]-\left[F^{-}\right]-\left[F_{H}\right]\right\} / \gamma_{3} \sum_{m K_{F m}^{o}}^{o}\left(F^{-}\right)^{m} \gamma_{n}^{-1}
$$

where $\left[F_{H}\right]$ is the concentration of fluoride complexed with H. 
The second equation makes a similar assumption to equation (1) except that it is derived from the conservation of mass of aluminium ${ }^{8}$ :

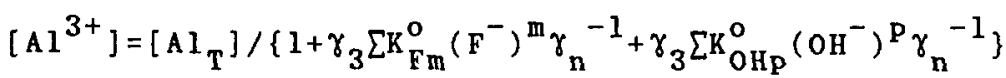

Where $p$ is the number of moles of oH forming complexes with Al that have equilibrium constants denoted by $\mathrm{K}_{\mathrm{OHp}}^{\circ}$.

The third equation assumes that the equilibrium in solution may be described by the law of electroneutrality of solutions. The equation is rearranged in terms of $\left[\mathrm{Al}^{3+}\right]$ with the concentrations of Al complexes expressed in terms of their equilibrium constants, $[A 1] \gamma_{3},\left(F^{-}\right)$and $\gamma_{n}$ :

$\left.[\mathrm{Al}]^{3+}\right]=\mathrm{a} /\left\{3+3 \gamma_{3} \sum \mathrm{nK} \mathrm{Fm}^{o}\left(\mathrm{~F}^{-}\right)^{\mathrm{m}} \gamma_{\mathrm{n}}^{-1}+\gamma_{3} \sum \mathrm{nK} \mathrm{OHp}^{o}\left(\mathrm{OH}^{-}\right)^{\mathrm{p}} \gamma_{n}^{-1}\right\}$

Where $\mathrm{a}^{-}=\left[\mathrm{F}^{-}\right]+\left[\mathrm{OH}^{-}\right]+\left[\mathrm{Cl}^{-}\right]-\left[\mathrm{H}^{+}\right]-\left[\mathrm{K}^{+}\right]$

The complexes of $A l$ with $F$ and $O H$ included in equations (1) - (3) were the same as those included in the calculations made by QELIOS.

\section{Competition between Humic Acid and $F$ for Al}

We studied the effect of six concentrations of two types of humic acid on the complexing between equimolar quantities of $A I_{T}$ and $F_{T}$ at $p H 4$ and 6 . The ratio of humic acid and $F$ cannot be expressed in molar quantities because the molecular weight of the humic acid is unknown. Hence, the quantities of humic acid will be expressed in terms of cmoles of cation exchange capacity ( $i$.e. the number of negative charges in Cmoles).

The first humic acid was extracted from a peat soil with cold $\mathrm{NaOH} 12,6$. A stock solution of humic acid was 
prepared by shaking $\mathrm{lg}$ in $500 \mathrm{ml}$ of $0.05 \mathrm{M} \mathrm{K} \mathrm{K}_{3}$ for 16 hours. The solution was filtered $(<0.45 \mu \mathrm{m})$ and treated with $\mathrm{H}^{+}$-saturated Bowex resin to remove excess $K$ and lower the $\mathrm{pH}$ to 4 . The percent carbon content (dichromate oxidation method) and the total exchange capacity ${ }^{17}$ were determined. Two ml of $2000 \mu \mathrm{M}$ stock solution of $\mathrm{AlCl}_{3}$ were mixed with $2 \mathrm{ml}$ of $2000 \mu \mathrm{M} \mathrm{KF}$ solution. Volumes of the humic acid stock solution, sufficient to give ratios of cmoles of humic acid: $F$ of $0: 1,9: 10,9: 1,26: 1,42: 1$ and $60: 1$, were added to the Al-F solution and the $\mathrm{pH}$ was adjusted to $\mathrm{pH} 4$ with $0.1 \mathrm{M}$ HCl. Each sample volume was made up to $20 \mathrm{ml}$ with deionised water and $0.05 \mathrm{M} \mathrm{KCl}$ to give a final concentration of $0.005 \mathrm{M}$. Duplicate samples were shaken for $16 \mathrm{~h}$, filtered $(<0.45 \mu \mathrm{m})$ and analysed for $A I_{T}$ by flame atomic absorption spectrophotometry and for $\left(F^{-}\right)$and $\left[F_{T}\right]$ with an orion ion selective electrode as described by Moore and Ritchie $\mathrm{R}^{1}$. $\mathrm{pH}$ was measured with a Beckman 171 research $\mathrm{pH}$ meter.

The experiment was repeated with humic acid extracted from a peat soil by $\mathrm{Na}_{2} \mathrm{H}_{2} \mathrm{P}_{2} \mathrm{O}_{7} 12$. Humic acid: F ratios of $0: 1,1: 1,5: 1,10: 1,20: 1$ and $28: 1$ (at pH 4 on (y) were used.

In both experiments, $\left[\mathrm{Al}^{3+}\right]$ was estimated by Equation (1) and the concentration of Al-humate was estimated from:

$$
\left.[A 1-h u m]=\left[A 1_{T}\right]-\left[A 1^{3+}\right]-\left[A 1_{O H}\right]-[A]_{F}\right]
$$

Equation (4) estimates the total amount of Al complexed with humate and makes no assumptions about the stoichiometry of the complexes. The Al-OH and Al-F species were the same as those considered in the previous section. The ability of some carboxylic acids (see Table 1) to compete with F for Al at pH 4 was 
TABLE I

Complexes of Simple Carboxylic Acids with Al used in QELIOS to Estimate the Ability of Organic ligand to Compete with $F$ for Al.

Ligand, I Complexes formed

$\log \mathrm{K}^{\circ}$ of 10

formation

\begin{tabular}{|c|c|c|}
\hline Malate & $A I+L=A I L$ & 5.79 \\
\hline \multirow[t]{3}{*}{ Salicylate } & $A I+L=A I L$ & 14.37 \\
\hline & $A I+2 L=A l L_{2}$ & 24.67 \\
\hline & $A 1+3 L=A 1 I_{3}$ & 30.29 \\
\hline \multirow[t]{3}{*}{ Gluconate } & $A 1+L=A I L$ & 2.71 \\
\hline & $A l+L=A I\left(H_{-}\right) L+H^{+}$ & 0.088 \\
\hline & $\mathrm{Al}+\mathrm{L}=\mathrm{Al}\left(\mathrm{H}_{-3}^{-1}\right) \mathrm{L}^{-}+3 \mathrm{H}^{+}$ & -9.20 \\
\hline \multirow[t]{3}{*}{ Citrate } & $A I+I=A I L$ & 10.18 \\
\hline & $\mathrm{Al}+\mathrm{H}+\mathrm{L}=\mathrm{A} 1 \mathrm{HL}$ & 13.12 \\
\hline & $\mathrm{Al}+\mathrm{L}=\mathrm{Al}\left(\mathrm{H}_{-1}\right) \mathrm{L}+\mathrm{H}^{+}$ & 6.63 \\
\hline
\end{tabular}

estimated by using QELIOS. The conditions were the same as used in the above two experiments except that the ratios of cmoles of carboxylic acid: F varied from 0.5 to 10. The organo-Al complexes and their log $K^{\circ}$ of formation are given in Table 1.

\section{RESULTS AND DISCUSSION}

Estimation of $\left[\mathrm{Al}^{3+}\right]$ from the Activity of Free Eluoride, $\left(F^{-}\right)$

Equation (2) for estimating $\left[\mathrm{Al}^{3+}\right]$ was the only procedure that agreed with the estimate of $\left[\mathrm{Al}^{3+}\right]$ made 
TABLE 2

Comparison of Methods of Calculation of $\left[\mathrm{A1}{ }^{3+}\right]$ for a Solution Containing $100 \mu \mathrm{M} \mathrm{AlCl} 3$ at $\mathrm{pH} 4$ and $I=0.005 \mathrm{M}$ and Various $A I_{T}: F_{T}$ ratios.

\begin{tabular}{|c|c|c|c|c|c|}
\hline \multirow{3}{*}{$A l_{T}: F_{T}$} & \multirow[t]{3}{*}{$\left(\mathbf{F}^{-}\right)^{*}$} & \multicolumn{4}{|c|}{$\left.[\mathrm{A}]^{3+}\right] \mu \mathrm{M}$} \\
\hline & & \multicolumn{4}{|c|}{ Methods of Estimation } \\
\hline & & QELIOS & $\mathrm{Eq}(1)$ & Eq (2) & $\mathrm{Eq}$ (3) \\
\hline$\infty$ & 0 & 91 & - & - & - \\
\hline 10 & 0.022 & 81 & 68 & 81 & 60 \\
\hline 5.0 & 0.048 & 72 & 62 & 71 & 55 \\
\hline 2.5 & 0.116 & 56 & 49 & 53 & 44 \\
\hline 1.3 & 0.352 & 30 & 26 & 27 & 25 \\
\hline 1.0 & 0.686 & 17 & 15 & 15 & 15 \\
\hline 0.5 & 9.48 & 0.37 & 0.37 & 0.36 & 0.65 \\
\hline
\end{tabular}

Estimated by QELIOS

by QELIOS at all the $A I_{T}: F_{T}$ ratios investigated (Table (2).

Equations (1) and (3) underestimated $\left[A 1^{3+}\right]$ by $13-$ $16 \%$ and $21-26 \%$, respectively, at $A 1_{T}: F_{T}$ ratios of $2.5-$ 10. At $A l_{T}: F_{T}=10$, the concentration of $A 1^{3+}$ should not be more than $10 \mu \mathrm{M}$ less than in the absence of $F_{T}$ because there is no $A 1-F$ complex known to contain more Al than $F$ per mole. However, $\left[\mathrm{Al}^{3+}\right]$ estimated by equation (1) at $\mathrm{Al}_{\mathrm{T}}: \mathrm{F}_{\mathrm{T}}=10$ was $23 \mu \mathrm{M}$ less than $\left[\mathrm{Al}^{3+}\right.$ ] at $A l_{T}: F_{T}=\infty$ (Table 2). Presumably, $\left[A 1^{3+}\right]$ calculated by equation (1) did not agree with the estimate made by QELIOS because the former method only estimates speciation from the mass balance of one component (i.e. F). QELIOS estimates speciation by simultaneously solving mass balance equations for all components in 
the system (i.e. K, Cl, Al, F). The simplified approach of equation (l) only appears to be valid when $A l_{T}: F_{T} \sim 1$. The agreement of equation (2) with QELIOS is probably a fortuitous result of the choice of $A 1: F$ ratios. If ratios $<1$ had been chosen, a similar disagreement with QELIOS would have been observed.

The $A l_{T}: F_{T}$ ratios in acid soil solutions tend to be $>1$ because of low $F$ concentrations ${ }^{13}$. Hence equations (1) and (3) would be of limited use for estimating $\left.[\mathrm{A}]^{3+}\right]$ in acid soils. Even though estimates of $\left[\mathrm{Al}^{3+}\right.$ ] made by equation (2) agreed with those made by QELIOS, a detailed chemical analysis of the soil solution would have to be made before the equation could be used because it assumes that the concentrations of all forms of Al in solution are known.

When the $A l_{T}: F_{T}$ ratio $=1$, the estimates of $\left[\mathrm{Al}^{3+}\right]$ by all the methods were in reasonable agreement with that calculated by QELIOS. Therefore equation (1) was suitable for estimating $\left[\mathrm{Al}{ }^{3+}\right]$ in the competition studies because equimolar concentrations of $A I_{T}$ and $F_{T}$ were used in all the experiments.

\section{Competition Between Humic Acid and Fluoride for}

\section{Aluminium}

For both types of humic acid, the percentage of $\mathrm{Al}_{\mathrm{T}}$ complexed with $F$ decreased as the ratio of humic acid: $F$ increased (Fig. 1). In the absence of humic acid, 78 and $42 \%$ of $\left[\mathrm{Al}_{\mathrm{T}}\right]$ is complexed with $\mathrm{F}$ at $\mathrm{pH} 4$ and 6 , respectively. At humic acid: $F$ ratios $\leq 1$, the speciation of $A l$ in the presence of both $F$ and humic acid was complicated by precipitation. The extent of precipitation appeared to depend on how the $\mathrm{pH}$ of the solution and $p K$ of association of the humic acid affected the Al:humic acid ratio in solution. 


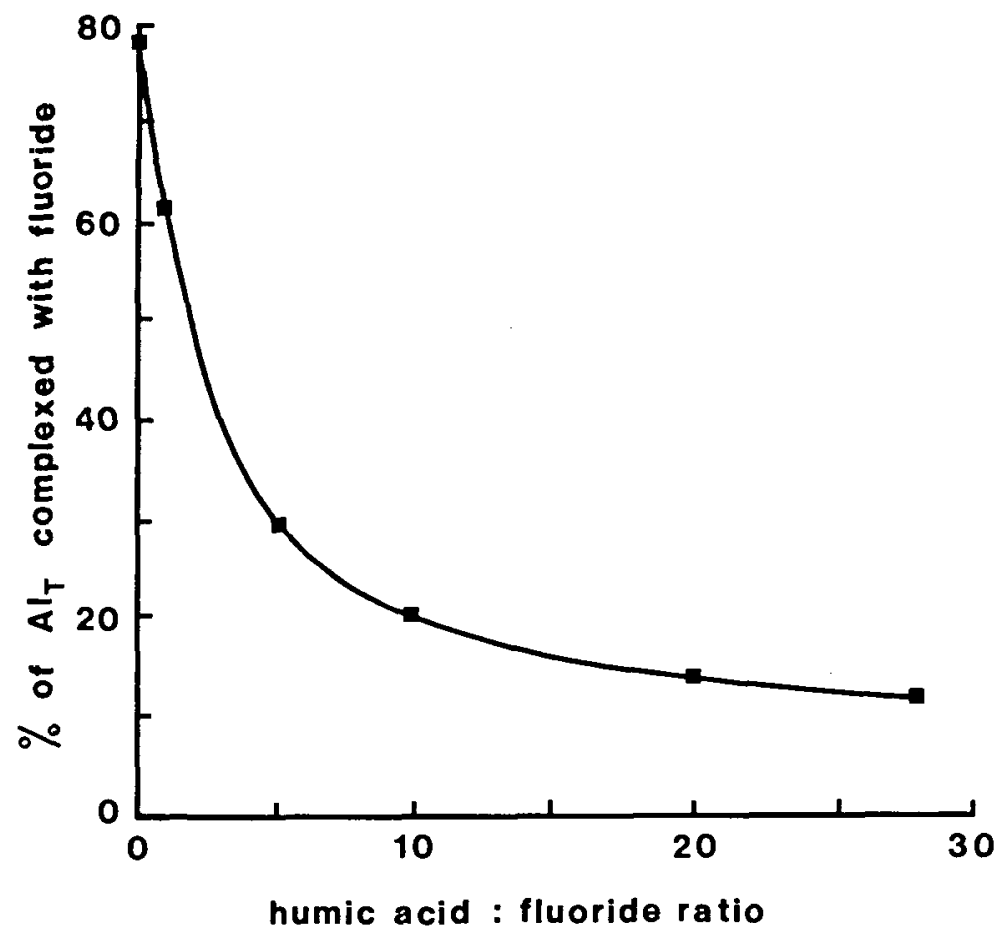

Fig.l The percentage of $\left[\mathrm{Al}_{\mathrm{T}}\right]$ complexed with $F$ as a function of the ratio of Cmoles of $\mathrm{Na}_{2} \mathrm{H}_{2} \mathrm{P}_{2} \mathrm{O}_{7}$
extractable humic acid: $\mathrm{F}$ at pH4.

At $\mathrm{pH} 4$ and a humic acid:F ratio of 0.9 all the $\mathrm{NaOH}$ extractable humic acid and $30 \%$ of the $\left[\mathrm{Al} \mathrm{T}_{\mathrm{T}}\right]$ originally present precipitated, resulting in the formation of a clear and colourless supernatant solution. No precipitation of Al would occur at this $\mathrm{pH}$ in the absence of humic acid which suggests that the precipitate was an Al-humate complex.

Ritchie et al ${ }^{5}$ observed that Al-humate complexes precipitated out of solution when the ratio of cmoles of Al:humic acid was $>1$. Under the conditions in this experiment, the Al:humic acid ratio is 3.3 if one 
assumes that all the $A l$ is available to react with all the humic acid. In reality, the amount of Al available to react with humic acid was probably decreased by complexing with $F$ and the amount of humic acid available to react with Al was decreased by competition between $A I$ and $H$. Both these factors would decrease the extent of Al-humate formation but would not necessarily change the effective Al:humic acid ratio.

A precipitate was also observed at $\mathrm{pH} 6$ when the $\mathrm{NaOH}$ extractable humic acid: F ratio was 0.9 but the supernatant was coloured indicating that some humic acid remained in solution. Fifty three percent of $\left[A 1_{T}\right]$ was precipitated whereas $>95 \%$ of $\left[A 1_{T}\right]$ would be expected to precipitate at pH 6 in the absence of humic acid and $F$. In this case, the precipitate could have been a mixture of $\mathrm{Al}(\mathrm{OH})_{3}$ and $\mathrm{Al}$-humate. The increased solubility of $A I$ in the presence of humic acid and $F$ was presumably caused by complex formation with both ligands. The increased solubility of the Al humate complex could be due to the effective ratio of Al:humic acid being < 3.3 because the 1 igand is more dissociated and the $A l$ is less soluble at $\mathrm{pH} 6$ than at $\mathrm{pH} 4$.

No precipitation was observed at $\mathrm{pH} 4$, when the $\mathrm{Na}_{2} \mathrm{H}_{2} \mathrm{P}_{2} \mathrm{O}_{7}$ extractable humic acid: $\mathrm{F}$ ratio was 1 . Pyrophosphate extractable humic acid is more dissociated at $\mathrm{pH} 4$ than $\mathrm{NaOH}$ extractable humic acid 12 and therefore the effective Al:humic acid ratio would be $<3.3$.

\section{At humic acid:F ratios $>1$, no precipitation} occurred and both humic acids decreased Al-F complexing by 21-100\%. There was no difference in the ability of the two types of humic acid to compete with F for Al at pH 4 when humic acid:F was $>10$ (Fig. 2). The sodium hydroxide extractable humic acid was able to compete more effectively with F for Al at $\mathrm{pH} 6$ than at $\mathrm{pH} 4$, 


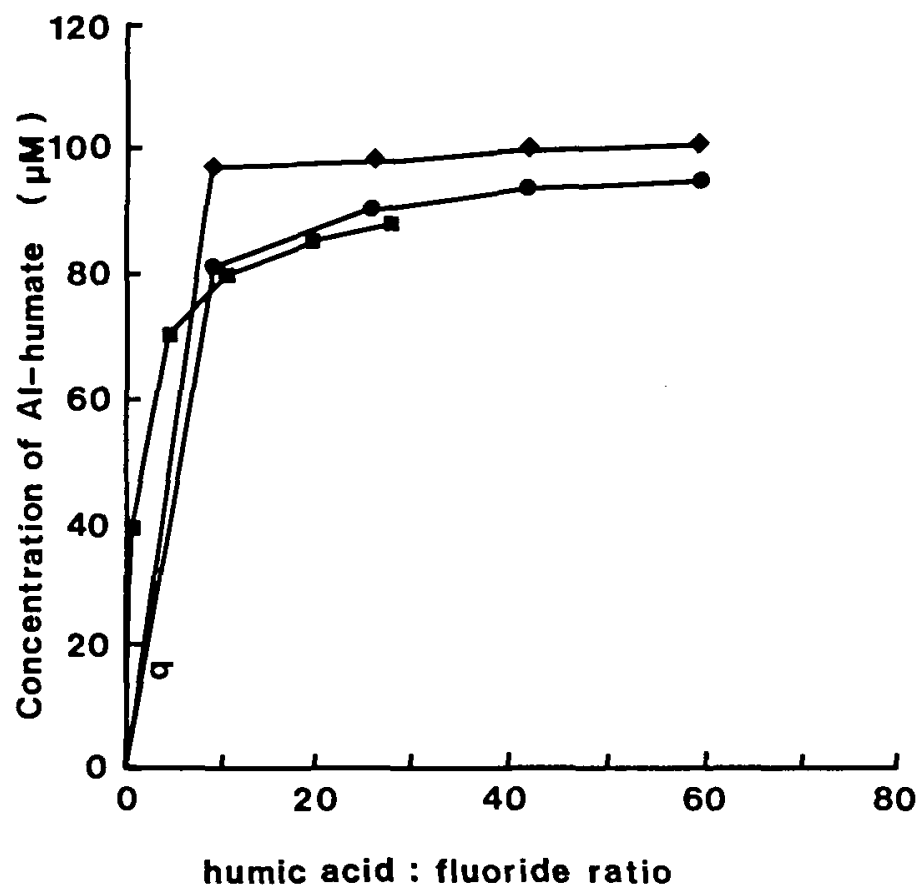

Fig. 2 The concentration of Al ( $\mu M)$ complexed with humic acid extracted by $\mathrm{NaOH}$ at $\mathrm{pH} 4$ (O) and $\mathrm{pH} 6$ (-) and humic acid extracted by $\mathrm{Na}_{2} \mathrm{H}_{2} \mathrm{P}_{2} \mathrm{O}_{7}$ at $\mathrm{pH} 4$ (E) as a function of the ratio of cmoles of humic acid: F.

presumably because $F$ does not complex Al as strongly at the higher $p H$. The competition between humic acid and F for Al may be put in perspective by considering the behaviour of simpler carboxylic acids. In the presence of $F$, the humic acids were able to complex more Al than all the simple carboxylic acids it was compared with (Fig. 3).

In acid soil solutions, humic acid: $F$ ratios are likely to be $>10$ and hence humic acids could play a greater role in controlling soluble $\mathrm{Al}_{\mathrm{T}}$ concentrations 


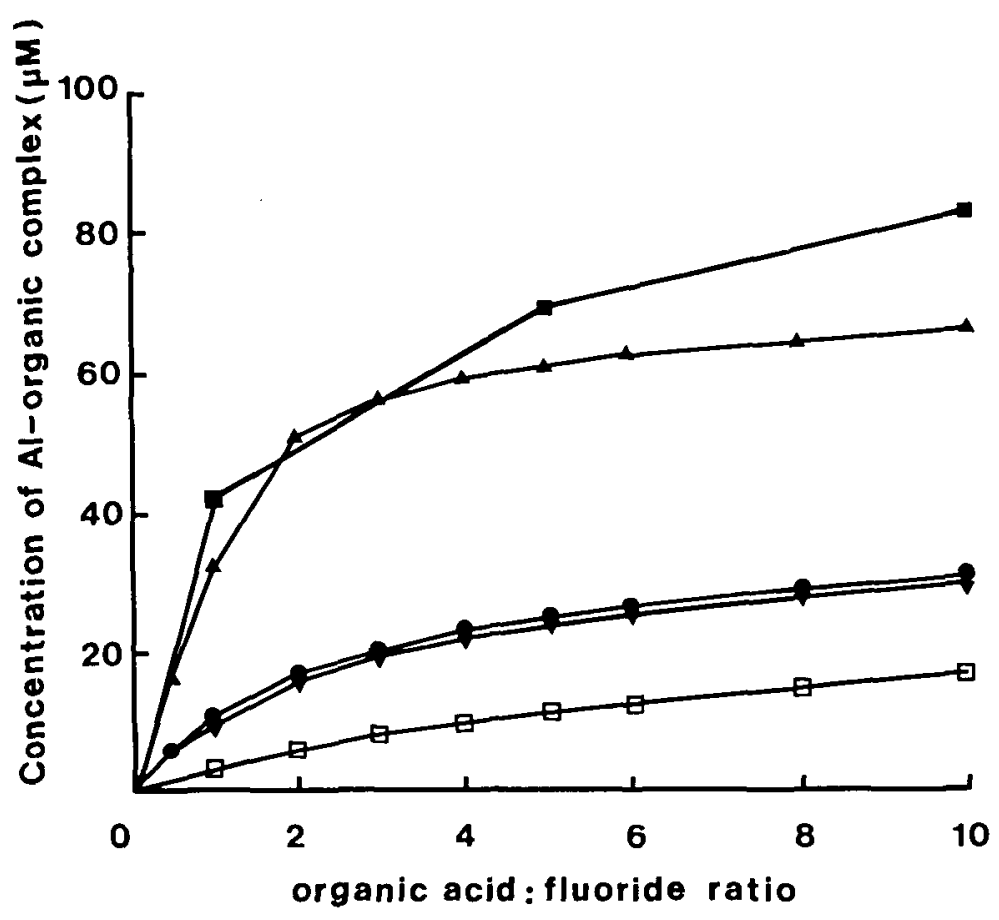

Fig. 3 The concentration of $A 1$ ( $\mu M)$ complexed with $\mathrm{Na}_{2} \mathrm{H}_{2} \mathrm{P}_{2} \mathrm{O}_{7}$ extractable humic acid ( $)^{2}$ ), citric ( $\Delta$ ), malic $(\nabla)$, salicylic (O) and gluconic ( $(0)$ acids at pH 4 as a function of the ratio of Cmoles of organic acid: F.

than F. Therefore, it will be more important to develop analytical techniques that can distinguish between $A 1$-humate and $\mathrm{Al}^{3+}$ rather than distinguish between $A I-F$ and $A^{3+}$

\section{CONCLUSIONS}

Equations (1) and (3) underestimated $\left[A 1^{3+}\right]$ at $A l_{T}: F_{T}$ ratios $>1$. These ratios are commonly found in acid soils and therefore may limit the application of equations ( 1 ) and ( 3 ) as procedures for estimating $\left.[A]^{3+}\right]$ in acid soil solutions. 
Equation (2) did not underestimate $\left[A 1^{3+}\right]$ over the range of $A l_{T}: F_{T}$ ratios studied but is of limited application to soil solutions because it assumes that all forms of $A 1$ in solution have been identified and their concentrations determined.

In acid soil solutions, humic acids are more likely to control Al speciation than F because they can compete successfully with $F$ for Al at humic acid:F ratios $>1$.

\section{REFERENCES}

1. Black, C.A. 1965. Methods of Soil Analysis, part 2. Am. Soc. of Agron., Madison, Wis.

2. Cameron, R.S., Ritchie, G.S.P. and Robson, A.D. 1986. Relative toxicities of inorganic aluminium complexes to barley. Soil Sci. Soc. Am. J. 50: $1231-1236$.

3. Campbe11, P.G.C., Bisson, M., Bougie, R., Tessier, A. and Villeneuve, J.P. 1983. Speciation of aluminium in acidic fresh-waters. Anal. Chem. 55: 2246-2252.

4. David, M.B. and Driscoll, C.T. 1984. Aluminium speciation and equilibria in soil solutions of a haplorthod in the Adirondack mountains. Geoderma 33: $297-318$.

5. Hodges, S.C. 1987. Aluminium speciation: A comparison of five methods. Soil Sci. Soc. Am. J. 51: $57-64$.

6. Hue, N.V., Craddock, G.R. and Adams, F. 1986. Effect of organic acids on aluminium toxicity in subsoils. Soil Sci. Soc. Am. J. 50: 28-34.

7. James, B.R., Clark, C.J. and Riha, S.J. 1983. An 8-hydroxyquinoline method for labile and total aluminium in soil extracts. Soil Sci. Soc. Am. J. 47: $894-897$.

8. Lazerte, B.C. 1984. Forms of aluminium in acidified catchments of Central Ontario: a methodological analysis. Can. J. Fish. Aquat. Sci. 41: $766-776$. 
9. Lindsay, w.L. 1979. Chemical equilibria in soils. John Wiley and Sons, New York.

10. Martel1, A.E. and Motekaitas, R.J. 1987. Coordination chemistry and speciation of Al(III) in aqueous solution. ACS Symposium, New orleans, Sept 1987: in press.

11. Moore, C.S. and Ritchie, G.S.P. 1988. Aluminium speciation and pH of an acid soil in the presence of fluoride. J. Soil Sci. 39: in press.

12. Posner, A.M. 1966. The humic acids extracted by various reagents from a soil. J. Soil Sci. 17: 65-78.

13. Ritchie, G.S.P. 1988. The chemical behaviour of aluminium, hydrogen and manganese in acid soils. In A.D. Robson (ed.) Soil Acidity and Plant Growth. Academic Press, Sydney. In press.

14. Ritchie, G.S.P. and Jarvis, S.C. 1986. Effects of inorganic speciation on the interpretation of copper adsorption by soils. J. Soil Sci. 37: 205210.

15. Ritchie, G.S.P., and Posner, A.M. and Ritchie, I.M. 1982. Polarographic study of the equilibrium between humic acid and aluminium in solution. J. Soil Sci. 33: 671-677.

16. Sposito, G. 1981. The thermodynamics of soil solutions. Clarendon Press, Oxford.

17. Young, S.D., Bache, B.W., Welch, D. and Anderson, H.A. 1981. Analysis of the potentiometric titration of natural and synthetic polycarboxylates. J. Soil Sci. 32: 579-592. 